Volume 10, No.1, January - February 2021

International Journal of Advanced Trends in Computer Science and Engineering

Available Online at http://www.warse.org/IJATCSE/static/pdf/file/ijatcse541012021.pdf

https://doi.org/10.30534/ijatcse/2021/541012021

\title{
Design of a Smart Classroom with Audio Visual (AV) Infrastructure for academic institutions to Enable Collaborative Learning
}

\author{
Dr. Sanjith S L \\ Systems Administrator, ICT Department, Indian Institute of Management Tiruchirappalli, Tamilnadu, India, \\ sanjithsl@gmail.com
}

\begin{abstract}
Abstract: Smart classrooms are basically the rooms wherein students come together in a shared space to construct, manipulate, and negotiate meaning around a canvas. This enables collaborative learning in the most effective manner. The environments become immersive learning happens on walls, desks, tables, and in conversations. The interactive surfaces become shared perceptual spaces where students discuss meaning and clarity and come to a collective understanding. When there is an environment with touch screens dedicated to creating opportunities for shared perceptual meaning, the students could dig down and construct knowledge in a deeper way. If you want students exchanging, collaborating, and talking synchronously in class then shared public spaces should be the primary focus of work. There are many techniques and options for setting up a smart classroom. Depending on the requirement and fund availability, the features and technology can be chosen. The requirements in a school would be less in terms of cost and technology as the school student would not be much well versed with the technological platforms. In this paper we have discussed about a smart class room that could provide an automated interactive learning environment for a modernized classroom of a school.
\end{abstract}

Key words: Smart classroom, collaborative learning, interactive learning, modernized classroom

\section{INTRODUCTION}

New practices have to be implemented in teaching and learning that build on the recognition of the powerful impact that school design has on how well students do at school, by creating flexible learning spaces or 'smart classrooms' designed to suit the individual needs of every student. Learning environments that are stimulating for students, support quality teaching and new technology have started changing the perspective of teaching and learning. Hence, technology enabled classrooms have become a necessity in the present scenario in school learning environment. The schools that are having well equipped classrooms are going to attract the students to join that institute as the technology would enable self learning as well.

The classroom that has an internet connection will enable the students to gather information from internet to get their doubt clarified without any help from a teacher. It would be more effective if there is WiFi along with a tablet for the students. In few of the states in India, the government has started providing tables and laptops to the school students in a subsidized rate. But it is not going to make any change in the learning environment unless and until there are smart learning environment in the classrooms. Google has launched e-learning platform called Google classroom for the students and teachers for automating the collaborative learning process which is totally a free application for the academic institution. Apart from Google classroom, there are other proven free/ open source applications like moodle that could also be used for the digitalized interactive learning.

Open source digital library applications like D-space and greenstone are also available for the students which can be setup in any school without spending any expense for this software. A basic server and a LAN connectivity would be the minimum requirement for setting up an in-house digital library in a school. How many institutes are using such free services in our state is the biggest question. It has become a challenge to educate the teachers to get equipped with such free resources available for the effective teaching and learning without which the technology is going to be accessible only for group of students who study in schools that have international standards.

When we talk about the construction of a smart classroom, there are few basic parameters that are to be considered to avoid unnecessary expenses and for proper utilization/effectiveness. A smart classroom is a classroom that has an instructor equipped with computer and Audio Visual equipments, empowering the instructor to teach using a wide variety of media. Smart class is a digital initiative, which is rapidly transforming the way teachers teach and 
students learn. With the help of school curriculum, smart classes bring in technology right next to the blackboard for teachers in the classroom. This makes learning an enjoyable experience for the students while improving their overall academic performance in school.

\section{INFRASTRUCTURE AND PREREQUISITES FOR TECHNOLOGY INTEGRATION}

Providing prerequisites is an important aspect to be considered before building a smart classroom. A reflective space, where students might work by themselves, or in a group of up to three, would be acoustically and visually private, with movable tables and comfortable seating. A creative space for small groups of three to five students would include round tables, storage for student's work and resources, and a display and projection area. An interactive space for larger groups of up to 75 students - could include space to allow team-teaching and collaborative learning, with large screens and display areas, allow for noise, and include movable furniture and links to outdoors. During the civil construction/renovation of the room wherein smart classroom is going to be made, civil aspects like acoustic treatment, ventilation, external noise avoidance etc to be considered. Concealed LAN ports and electrical connections are also to be provided during the construction of the building. The seating arrangement and movable chairs would make the smart classrooms more dynamic and beautiful which would also make the students more comfortable with the learning environment.

Let us now start discussing about the technicalities of a smart classroom interms of Audio and Video infrastructure. Smart classroom includes (but not limited to) interactive board/Interactive Projectors/Interactive Displays, Visualizer/ document camera, Audio systems (Speakers \& Microphones), Internet connectivity, Video Conferencing software/hardware, PPTs and more, all displayed through a data projector. In addition to the Audio Visual systems, the technologies like face recognition based attendance systems can also be incorporated in the smart classroom to ensure the active presence of the students. The details of the Audo and video components that could be incorporated in a smart classroom is detailed in the next section of this paper.

\section{AUDIO VISUAL INFRASTRUCTURE}
a. Audio Components
b. Video Components
c. Video Conferencing facility
d. Control units and AV automation
Integration of Audio, Video and Control
components

\subsection{Audio Components:}

There are different kind of Microphones which are essential for the bosting of volume of the faculty member without which the sound will not be audible to the entire classroom. The microphones can be used for the students as well so that the two way interaction will become more effective. The microphones can be classified as follows:

$\begin{array}{ll}\text { i. } & \text { Handheld microphones } \\ \text { ii. } & \text { Lapel Microphones } \\ \text { iii. } & \text { Boundary Microphones } \\ \text { iv. } & \text { Ceiling microphones } \\ \text { v. } & \text { Gunshot microphones } \\ \text { vi. } & \text { Beam forming microphone arrays } \\ \text { vii. } & \text { Condenser hanging microphones } \\ \text { viii. } & \text { Goose neck microphones etc. }\end{array}$

The polarization pattern of the microphones can be mainly classified into Omni directional, Cardioid, Super cardioid etc based on the angle of coverage. Based on the application, different types of microphones can be chosen. Local reinforcement is the process of capturing voice from the microphone and the same voice would be coming through the speakers in the same room. The suitable microphones with narrow polarization angle should be chosen for the local reinforcement to reduce the voice feedback. Handheld microphones are ideal for the students as the same will not create any feedback. Goose neck microphones are also good for the students for local reinforcement as the same can be adjusted to reduce the audio feedback. Boundry microphones are suitable for video conferencing applications. However, the same could be used for local reinforcement with low gain. Ceiling microphones with Cardioid and super cardioid patterns can be used for the video Conferencing applications. Ideally, this arrangement is not recommendable for the local reinforcement of the audio. However, if the acoustic treatment is very good, this could be used as an experiment for local reinforcement with a very less gain. Candensor hanging microphones is very ideal for the video conferencing ceiling based audio capturing as the capturing capacity is very high for the condenser hanging microphones and hence less number of mics can capture more area which would help us to reduce the cost. Bean forming microphone arrays will have multiple microphone elements in a single unit, the same will create a beam throughout the area, and the voice will be captured from that particular area.

Speakers are also very important components in setting up a smart classroom. There are several types of speakers and mainly it could be classified into two, which are active and passive. The active speakers are good for better amplification of the sound and the same could cover large area. Wall mount, ceiling mount and floor mount speakers are available based on the site condition and seating arrangements/applications. Subwoofers and tweeters can also be used for better quality of audio. Positioning of speakers plays an important role in the designing of smart classrooms. The speakers should be positioned such a way that the sound will be transmitted uniformly throughout the area. Line array speakers are the best option for big halls wherein more that 200 students have to be accommodated. 


\subsection{Video Components:}

The video Components that are used in the Smart classrooms are listed below:

$\begin{array}{ll}\text { i. } & \text { Professional Displays } \\ \text { ii. } & \begin{array}{l}\text { Interactive monitors with figure touch/pen } \\ \text { touch functionality }\end{array} \\ \text { iii. } & \text { Interactive displays } \\ \text { iv. } & \text { High resolution projectors } \\ \text { v. } & \text { Interactive projectors } \\ \text { vi. } & \text { Multi monitor displays arrangements } \\ \text { vii. } & \text { DNP Screens } \\ \text { viii. } & \text { Laser projection systems etc }\end{array}$

There are lot of innovative products launched in the last few years in the Audio Visual Infrastructure for setting up dynamic visual effects in the classroom environment. Professional displays are available for 24/7 operations which is useful for long duration applications. Professional displays comes with interactive functionalities, which enables the faculty to make the annotations and other interactive functions during the sessions.

High sensitive interactive monitors are also available for the faculties to take sessions through Video Conferencing using dual monitor arrangements. This would help the faculty to see the presenter in a non interactive monitor and the presentation in an interactive monitor which helps the faculties to have a face to face effect during online classes especially during the pandemic period.

There are LCD and LED projectors with high lumens and full $\mathrm{HD} / 4 \mathrm{~K}$ resolutions suitable for the classroom environment. There are multichip projectors with very high lumens which would be suitable for the large classroom setup. Since the lamp hours is less (1500 to 4000 Hours) for the LCD and LED projectors, laser projections systems could be used for long life that could provide about 20,000 lamp hours. There is a system called DNP projection system with gray screen which provides the quality of a display using a laser projection system. However, the white motorized screens are not suitable for high quality projection. However, motorized tab-tension screens are better than the conventional screens. There are interactive projectors that could projects on a matt finish board and annotations could be done on these projected surface either using figure or using light/digital pen.

\subsection{Video Conferencing facility}

The pandemic period has forced the faculty members to start using the digital platforms for the conduct of classes. New innovations have come up for making the online classes more interactive and flexible. The applications like zoom, webex, Google meet, MS Teams etc has incorporated new features for making flexibility in the online/virtual classrooms. The functionalities like breakout rooms, polls, attendance marking, recording etc has made the D2D (Direct to Desktop) sessions very effective. PTZ Cameras, motion detection cameras etc have made the online classes more dynamic and automated. The applications like light boards have also been launched for giving visual effects to the recorded lectures. Lecture capturing systems and playback applications incorporating Learning Management systems have given added benefits to the students for studying the lectures more effectively. There are free cloud applications like google classrooms to achieve this requirement.

\subsection{Control Units and AV Automation}

The Audio Visual components can be controlled using RS 232 connectors and IR connectors. This could be incorporated using Audio and Video processors for automation purpose. After automation, all the Audio and Video components including motorized screens can be controlled using a touch panel or button panel. The cameras can be controlled using a joystick and camera switches. DSP based mixer can be used for mixing the audio inputs, feedback suppression and Automatic Echo Cancellation. In addition to the same, manual mixers can also be used for controlling the audio input and output during the events. The automation will also help us to control the audio visual equipments from a remote location via a digital device like desktop, laptop or mobile phone.

\subsection{Integration of Audio, Video and Control components}

Integration of audio visual components is the major challenging job and the integration should be planned by the help of a diagram. Multiple revisions needs to be made after making the initial plan to avoid any missing requirement. An sample elevation of the writing board is given below for reference:

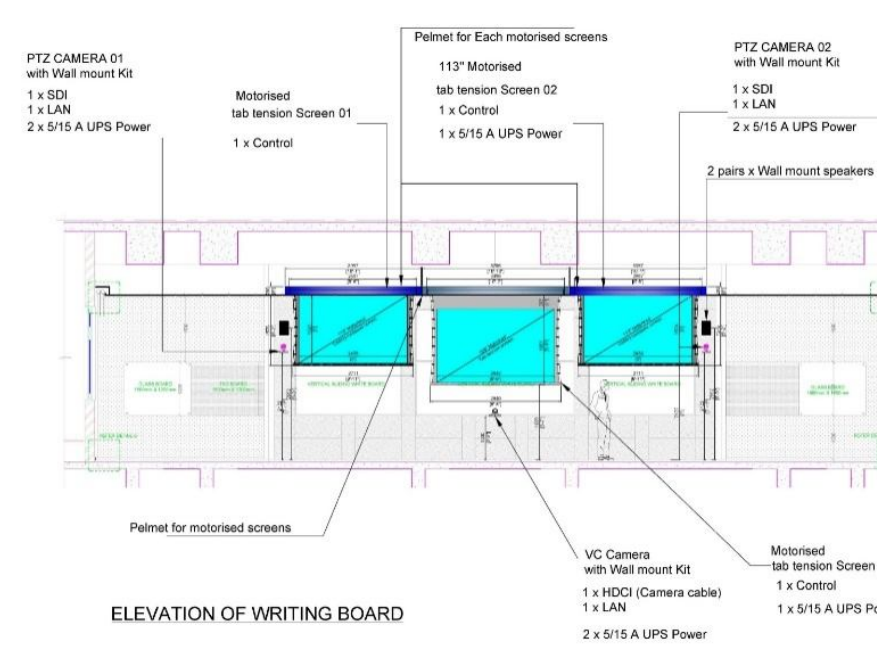

Figure 1 : Elevation of writing Board and Screen

In the above Elevation, three motorized screens are shown. During video Conferencing, the centre screen will show the presenter and the side screen will show the presentations. The arrangements of cameras and speakers are also given in the above drawing. 
The arrangements and positioning of Audio Visual Components (Reflected Ceiling Plan) in a classroom with circular seating arrangement is given below

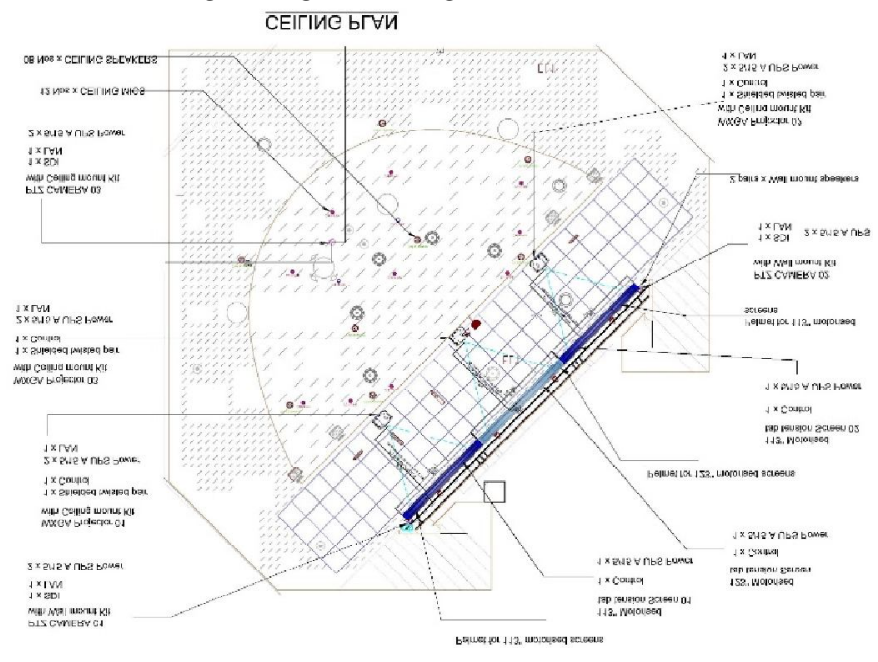

Figure 2 : Reflected Ceiling Plan of the classroom with circular seating arrangement

\section{CONCLUSION}

The challenges in designing the Audio Visual Infrastructure has been increased due to the technology innovations and increase in the usage of online resources \& IT enabled learning/teaching trends. Building an Audio Visual Infrastructure that could adapt all the requirement of digital learning is very essential during the present scenario as the IoT and IT enabled services are playing key role in the learning and teaching environment. The currentdesign/conceptsshows the best practices that has to be followed for setting up a state-of-the-art Audio Visual Infrastructure in an academic campus. There are variousapproaches and techniquesused in this paper for the development of an outstandingAudio Visual infrastructure design. According to the requirement and budget of the institute and it's structuralconditions, changes need to be madein this design.

\section{ACKNOWLEDGMENT}

I am grateful to my colleagues, post-graduation batch mates, technical experts and AV integrators whom I had consulted and my friends for the great support and service offered to me throughout this study.

\section{REFERENCES}

1. Askoy G.et al"The effects of animation technique on the 7th grade Science and Technology Course", Scientific Research Journal, Vol. 3, Issue. 3, PP. 304-308, 2012.

2. Yelin Kim, TolgaSoyata,Reza FeyziBehnagh,"Towards Emotionally-Aware AI Smart Classroom: Current Issues and Directions for Engineering and Education." IEEE Access,DOI: 10.1109/ACCESS.2018.2791861 , 2018.
3. Ranjit Kaur and Asha Yadav et al "Effectiveness of EduSmart Class Room on Academic Achievement Among Eighth Class Social Science Students",Vol. 4, Issue. 3, 2013.

4. Gupta M. and Parveshlata, "Effectiveness of IT-enabled instructional package(ITEIP) on science achievement of X class studentsin relation to their gender" British journal of Education, Vol. 2, Issue. 4, PP. 17-30, 2014.

5. Chachra I. K andAbhinav, "Effect of smartclassroom assisted teaching on academicachievement of students of different intelligencelevel in social science", National MonthlyRefereed Journal of Research in Arts andEducation, Vol. 4, Issue. 6, PP. 4-10, 2015.

6. GanyaupfuE.Met al, "Teachingmethods and students' academic performance", International Journal of Humanities and SocialScience Invention, Vol. 2, Issue. 9, PP. 29-35, 2013.

7. Daluba N. E. et al, "Effect ofdemonstration method of teaching on students'achievement in Agricultural Science" WorldJournal of Education, Vol. 3, Issue. 6, PP. 1-7, 2013.

8. Bano N, "Impact of smart classroom learning environment on theperformance of first grade students in English“,FUNOON- An International Journal of Multidisplinary Research, Vol. 2, Issue. 1, PP. 121-128, 2016.

9. Madhu Gupta and Kuldeep Singh,“ Effect of Smart Classroom Teaching On Achievement of Students: A Closer Focus on Gender and Intelligence ", Imperial Journal of Interdisciplinary Research (IJIR), Vol.3, Issue.1, 2017.

10. Manohari G, Thangavel and Shenbhagavadivu,“ A study on scope of smart class rooms in the government schools functioning in and around Coimbatore", International Journal of Management and Humanities (IJMH), Vol. 5, Issue. 4, 2018. 